\title{
Loading and fracture response of CFRP-to-steel adhesively bonded joints with thick adherents - Part II: Numerical simulation
}

\section{Anyfantis, Konstantinos; Tsouvalis, Nicholas G.}

\section{Published in:}

Composite Structures

Link to article, DOI:

10.1016/j.compstruct.2012.08.056

Publication date:

2013

Document Version

Publisher's PDF, also known as Version of record

Link back to DTU Orbit

Citation (APA):

Anyfantis, K., \& Tsouvalis, N. G. (2013). Loading and fracture response of CFRP-to-steel adhesively bonded joints with thick adherents - Part II: Numerical simulation. Composite Structures, 96, 858-868.

https://doi.org/10.1016/j.compstruct.2012.08.056

\section{General rights}

Copyright and moral rights for the publications made accessible in the public portal are retained by the authors and/or other copyright owners and it is a condition of accessing publications that users recognise and abide by the legal requirements associated with these rights.

- Users may download and print one copy of any publication from the public portal for the purpose of private study or research.

- You may not further distribute the material or use it for any profit-making activity or commercial gain

- You may freely distribute the URL identifying the publication in the public portal 


\title{
Loading and fracture response of CFRP-to-steel adhesively bonded joints with thick adherents - Part II: Numerical simulation
}

\author{
Konstantinos N. Anyfantis ${ }^{\mathrm{a}, *}$, Nicholas G. Tsouvalis ${ }^{\mathrm{b}}$ \\ ${ }^{a}$ Department of Wind Energy, Technical University of Denmark, Lyngby, Denmark \\ ${ }^{\mathrm{b}}$ Shipbuilding Technology Laboratory, School of Naval Architecture and Marine Engineering, National Technical University of Athens, Greece
}

\section{A R T I C L E I N F O}

\section{Article history:}

Available online 13 September 2012

\section{Keywords:}

Adhesive joints

Mixed-mode fracture

Debonding

Cohesive zone model

Cohesive elements

\begin{abstract}
A B S T R A C $T$
This work is focused on the numerical simulation of experimentally tested single lap joints, based on cohesive zone modeling techniques. Seven cases have been considered for analysis. The models were built in a 3-dimensional finite element space. The adherents were modeled with continuum elements whereas the entire adhesive layer has been modeled with cohesive elements. A mixed-mode cohesive model, which is an ideal candidate for describing the loading and fracture response of a relatively thin ductile adhesive layer, has been used as the constitutive relation of the cohesive elements. The traction increase part of the cohesive laws is given by an exponential function, which describes the elastoplastic adhesive response, and the traction decrease part is given by a linear function, which describes damage initiation and propagation. By using this model, it was achieved to calculate the developed peel, in-plane and out-of-plane shear stresses over the adhesive area. Thus, the global measured response of all cases was justified by examining the stress fields and their variation through the loading history.
\end{abstract}

(C) 2012 Elsevier Ltd. All rights reserved.

\section{Introduction}

Structural adhesive bonding is gaining more and more the interest of researchers and design engineers due to the advantages it offers compared to mechanical joining techniques, particularly when it comes to joining dissimilar materials, e.g. composites to metals. When it comes to the design of an adhesive joint, it is of great importance to investigate the level of cooperation of the materials involved, in terms of their adhesion properties, i.e. stiffness and strength. Thus, laboratory adhesive joints with simple geometrical configurations are adopted for testing and analysis purposes. Single lap joints (SLJs) with flat adherents are well preferred for this purpose, not only because they are relatively easy to fabricate and test, but also because there are several closed-form solutions available in the open literature that can be applied for the calculation of the developed stress fields within the adhesive layer. These models are collected in Refs. [1,2].

Analytical solutions for calculating the mixed-mode response of a moderately or highly non-linear adhesive layer (ductile material response) are not available. Thus, numerical solutions derived from finite element methods are at most preferable. Several methodologies can be found in the literature for the finite element analysis (FEA) of adhesive joints based on the technique followed for modeling the adhesive layer, its interaction with the adjacent sub-

\footnotetext{
* Corresponding author. Tel.: +45 45251382.

E-mail address: kanyf@dtu.dk (K.N. Anyfantis).
}

strates and its failure behavior. An adhesive layer typically fails under mixed-mode conditions by peel (Mode I), in-plane (Mode II) and out-of-plane (Mode III) shear stresses. When an adhesive joint is loaded, the developed stresses are being transferred from one substrate to the other through the adhesive and via the adhesive/adherent interface. Thus, two are the main macro-mechanical failure types involved in the adhesive bonded region, i.e. adhesive and cohesive failure.

Traditional simulation techniques are based on utilizing continuum elements for modeling both the adhesive and adherents [3$6]$. The faces of the adhesive elements are directly connected to the corresponding faces of the adherent elements, in the adhesive/ adherent interface. Either by using common nodes or by using multi point constraint techniques, perfect bonding conditions are assumed. In this way, shear and normal stresses are being transferred through the bi-material interface invariantly. This procedure is adequate for calculating the elastic and plastic response of the adhesive material in terms of the developed stresses, but neglects the stiffness and strength of the bi-material interface, which are important for determining the failure response and load of a joint. Stress or strain failure criteria can be utilized for the prediction of failure initiation and progression in the adhesive layer $[7,8]$ but such finite element models are mesh dependent, since stress concentrations usually develop at the edges of the adhesive region. However, several ways are proposed that can handle such issues [9-11].

Within the framework of linear elastic fracture mechanics, the Virtual Crack Closure Technique (VCCT) has been utilized for the 
numerical simulation of the failure behavior of adhesive joints $[12,13]$. However, VCCT is not appropriate in numerical predictions of adhesive joints with ductile adhesives, since it is oriented for linear elastic fracture mechanics problems.

Damage mechanics permit the simulation of step-by-step damage and fracture at a pre-defined crack path or arbitrarily within a finite region up to the complete structural failure, with the use of cohesive or interface elements. The available techniques for damage modeling can be separated into local or continuum approaches [14] (see Fig. 1). In the local approach, damage is confined to a zero volume line or a surface, allowing the simulation of an interfacial failure between the adhesive bond and the adherent or/and of a cohesive failure [15,16], as shown in Fig. 1a. By the continuum approach, the damage is modeled over a finite region along an adhesive bond to simulate a cohesive fracture of the adhesive bond [17]. Under this framework, Thouless and his coworkers $[18,19]$ have introduced the embedded process zone (EPZ) approach, according to which, the adhesive layer works as the continuum which provides and transfers tractions between the adherents. From the numerical point of view, the adhesive material is totally represented by interface or cohesive elements that can model the kinematics incorporated in the EPZ. The constitutive relations are given in terms of opening and shear traction-separation (T-S) laws under pure Mode I and pure Mode II loading and fracture, respectively. Campilho and de Moura [15,20,21] developed a cohesive mixed-mode damage model to predict the behavior of ductile adhesives with a trapezoidal shape T-S law representing loading and fracture of each fracture mode, within the framework of Elastic Plastic Fracture Mechanics.

A more realistic EPZ law and mixed-mode model have been recently developed by Anyfantis and Tsouvalis $[22,23]$ for the prediction of the mixed-mode response of ductile adhesive layers. The model has been validated with metal-to-metal [22-24] and composite-to-metal [25] adhesive joints and it has been concluded that it can adequately model the interaction between the adhesive and the adherents.

The present work is the second part of a paper series, that is focused on the investigation and study of the loading and fracture response of CFRP-to-steel adhesively bonded joints. The seven SLJ cases whose fabrication and testing is presented in the first part [26] have been considered herein for numerical simulation. The main objective of this study is to provide justifications of the experimentally measured response, by examining the developed stresses and their variation through the loading

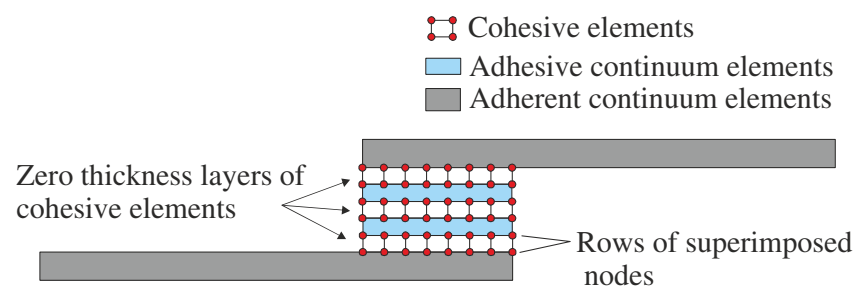

(a)

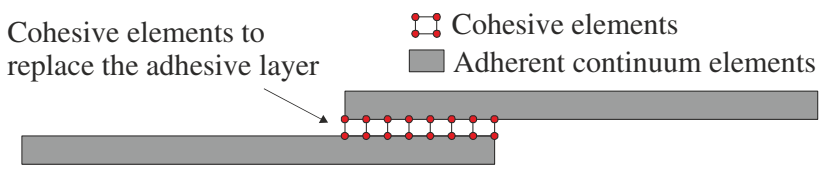

(b)

Fig. 1. Cohesive elements to simulate zero thickness failure paths - local approach (a) and to model thin adhesive bond between the adherents-continuum approach (b) in an adhesive bond. history. For this purpose the 3D EPZ mixed-mode model [23] has been utilized for the mathematical description of the adhesive's layer response.

\section{Mixed-mode cohesive zone model}

The loading and fracture response of a ductile adhesive layer, constrained between two continuum media, may be simulated with a cohesive zone model, within the framework of finite element methods. In this work, a recently developed mixed-mode model that accounts for the coupling and interdependency of pure mode EPZ laws has been utilized for the numerical simulation of the tested SLJ cases. This model has been formulated to describe the mixedmode response of an adhesive layer subjected to Mode I and II loading and fracture [22] and of an adhesive layer subjected to Mode I, II and III loading and fracture [23]. The authors have utilized the particular cohesive models, since these have proven to provide accurate predictions of the global response of adhesive joints with ductile adhesives. This is necessary, under the framework of the current work, since matching the numerical global responses of the tested joints with the corresponding experimental ones, will yield accurate predictions of the respective stress fields developing over the adhesive domain. However, working with CZM techniques towards predicting only the strength of joints, one should focus more on utilizing accurate values of the fracture toughness magnitudes, but still using intrinsic laws for ductile adhesives, i.e. exponential linear [22,23], and trapezoidal [16,20,21].

Uniaxial loading of single lap joints with flat adherents results in the development of peel and out-of-the loading plane shear stresses, in a way that the problem can be assumed plane strain; thus it would be natural to model such cases in a 2D simulation environment. However, preliminary finite element analysis of the tested SLJ geometries in a 2D and 3D space revealed that there is a significant effect of the out-of-the loading plane shear stresses on the failure of the adhesive layer, particularly for the cases where metal adherents enter plasticity. For this purpose, the results presented in this work are based on modeling the joints in a 3D environment by utilizing the Mode I, II and III mixed-mode EPZ model [23].

Fig. 2 shows the shapes and the corresponding parameters of the pure mode phenomenological EPZ laws, which are treated as the material properties of the adhesive layer. The traction increasing part (stress hardening) is mathematically given by an exponential function, which inherently describes the linear elastic, non-linear elastic and plastic response of the adhesive material. Magnitude $\sigma_{\mathrm{c}, i}$ represents the critical stress and magnitude $\delta_{0, i}$ is its corresponding separation at damage initiation. The linear elastic response is given by the initial stiffness $k_{i}$, which is directly defined for each mode by dividing the corresponding elastic constant of the adhesive material with the adhesive thickness, $k_{\mathrm{I}}=E_{\mathrm{a}} / t_{\mathrm{a}}, k_{\mathrm{II}}=G_{\mathrm{a}} / t_{\mathrm{a}}$ and $k_{\mathrm{III}}=k_{\mathrm{II}}$, where $E_{\mathrm{a}}$ and $G_{\mathrm{a}}$ is the Young and shear modulus of the adhesive, respectively, and $t_{\mathrm{a}}$ the adhesive thickness. The linear traction decreasing part, beyond $\sigma_{c, i}$, denotes the development of the fracture process zone, which occurs within the adhesive layer and in the adhesive/substrate interfaces, i.e. void nucleation, micro-cracking, micro-debonding and fibril deformation of the adhesive material. In order to avoid interpenetration between the, adjacent to the cohesive elements, continuum elements, a penalty contact algorithm has been included only in the formulation of Mode I EPZ law (see Fig. 2a). Magnitude $\delta_{\mathrm{c}, i}$ is the critical separation, beyond which tractions vanish, hence describing the formation of macro cracking and debonding. The total energy consumed at the end of the proposed EPZ law is given by the definite integral (area) of its curve, namely $J_{i c}$.

Having defined the pure mode EPZ laws (Mode I, II and III) as the material properties of the adhesive layer, these are next 


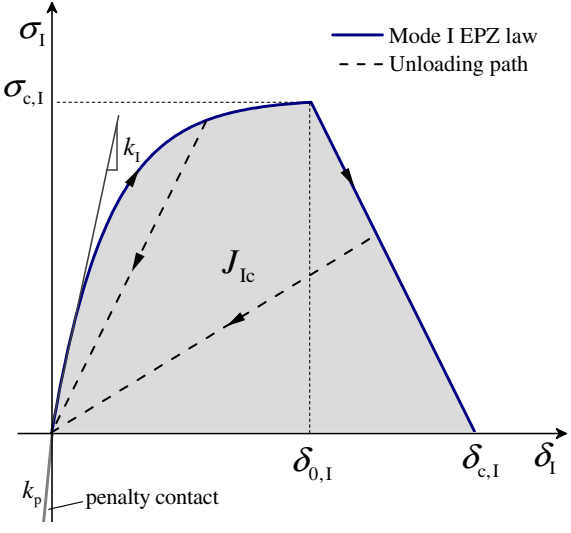

(a)

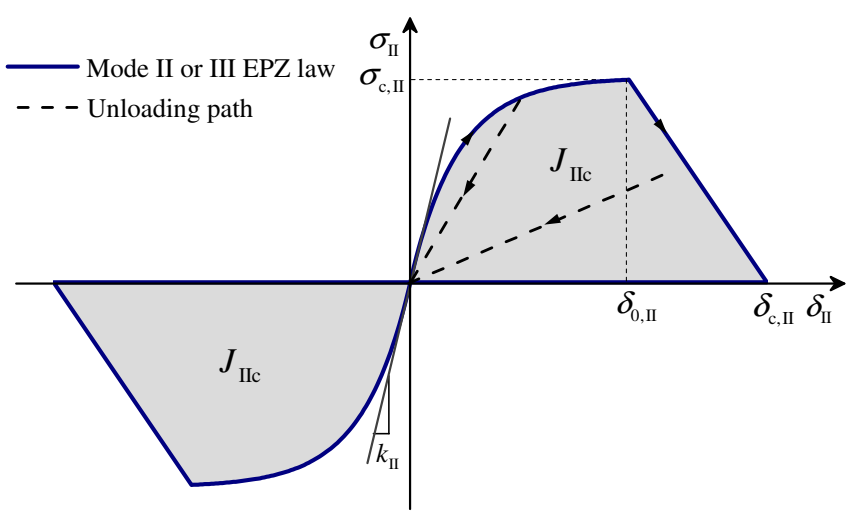

(b)

Fig. 2. Proposed EPZ laws for the prediction of Mode I (a) and Mode II or III (b) loading and fracture.

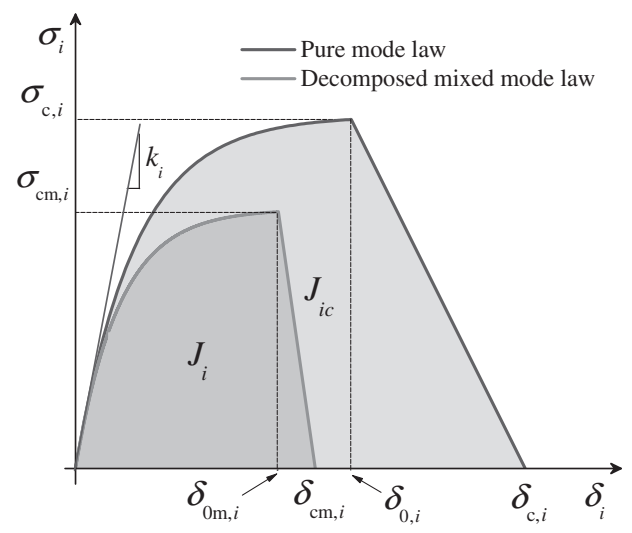

Fig. 3. Proposed 3D mixed-mode EPZ model ( $i=\mathrm{I}$, II or III). formulated under a 3D mixed-mode model that accounts for their coupling and interdependency, as shown in Fig. 3. Two cases are considered according to the sign of the normal tractions $\sigma_{\mathrm{I}}$, since positive tractions contribute to the loading and fracture and negative tractions denote contact in the adhesive bondline. Thus, one case considers the Mode I, II and III mixity (positive $\sigma_{\mathrm{I}}$ ) and the remaining one considers only Mode II and III mixity (negative $\sigma_{\mathrm{I}}$ ).

For the prediction of damage initiation and damage propagation under mixed mode conditions, the quadratic stress criterion and the linear energetic fracture criterion are considered, respectively [23]. The parameters of the decomposed laws, i.e. $\sigma_{\mathrm{cm}, i}, \delta_{0 \mathrm{~m}, \mathrm{i}}, \delta_{\mathrm{cm}, \mathrm{i}}$ and $J_{i}$ are being calculated according to the mode mixity ratios $\left(\delta_{\mathrm{II}} / \delta_{\mathrm{I}}\right.$ and $\left.\delta_{\mathrm{III}} / \delta_{\mathrm{I}}\right)$ at each Gauss point of the cohesive elements, through the loading history.

\section{Numerical modeling}

The actual average dimensions of the tested SLJ geometries, described in part I of this paper series, have been considered for finite element simulations. Such geometries involve seven cases that differ in the overlap length ( 25 or $75 \mathrm{~mm}$ ), in the adhesive thickness (nominal 0.5 or $0.8 \mathrm{~mm}$ ) and in the stiffness ratio ( 0.175 or 0.35 ), as listed in Table 1. Thus, seven models have been constructed in a 3dimensional space according to the mesh, loading and boundary conditions shown in Fig. 4. As far as the CFRP and steel adherents

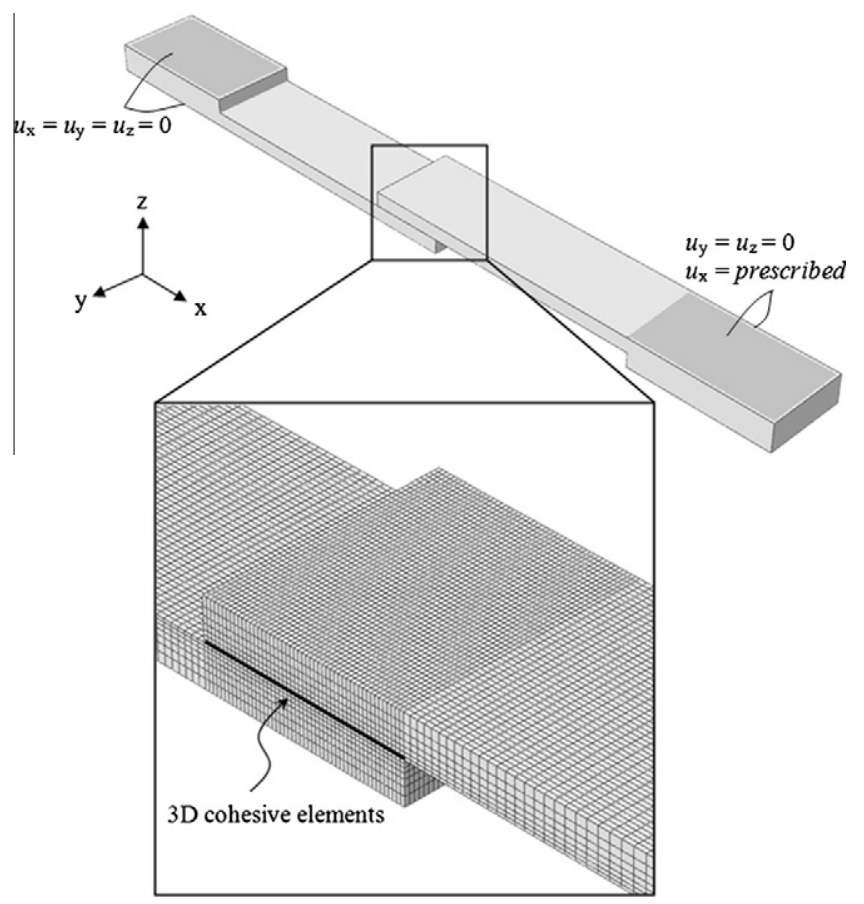

Fig. 4. Finite element model of a typical SLJ with boundary conditions and a detail of the overlap.

Table 1

SLJ cases considered in the parametric study.

\begin{tabular}{|c|c|c|c|c|c|c|c|}
\hline Case & $t_{\mathrm{c}}(\mathrm{mm})$ & $t_{\mathrm{s}}(\mathrm{mm})$ & $L_{\mathrm{t}}(\mathrm{mm})$ & $L_{\mathrm{a}}(\mathrm{mm})$ & $L_{\mathrm{o}}(\mathrm{mm})$ & $t_{\mathrm{a}}(\mathrm{mm})$ & $w(\mathrm{~mm})$ \\
\hline SLJ-1 & 7.98 & 8 & 40 & 75 & 75 & 0.52 & 23.76 \\
\hline SLJ-2 & 8.60 & 8 & 40 & 75 & 75 & 0.89 & 24.00 \\
\hline SLJ-3 & 9.56 & 5 & 40 & 75 & 75 & 0.51 & 23.93 \\
\hline SLJ-4 & 9.29 & 5 & 40 & 75 & 75 & 0.84 & 23.89 \\
\hline SLJ-5 & 9.99 & 5 & 40 & 75 & 25 & 0.51 & 23.83 \\
\hline SLJ-6 & 9.99 & 5 & 40 & 75 & 25 & 0.85 & 23.99 \\
\hline SLJ-7 & 8.12 & 8 & 40 & 75 & 25 & 0.50 & 24.04 \\
\hline
\end{tabular}


are concerned, quadratic 20-node brick elements (C3D20) available in the ABAQUS ${ }^{\circledR}$ element library have been utilized. The whole adhesive layer is represented by 16 -node plane cohesive elements (placed between adjacent continuum elements in the overlap areas), programmed in a UEL (User Element Subroutine) subroutine. The cohesive elements utilized have constant dimensions $(0.5 \times 0.5) \mathrm{mm}^{2}$ in the entire overlap areas. For the numerical integration of the stiffness matrix and the internal force vector, a $3 \times 3$ Gaussian quadrature rule has been used. The Newton-Raphson method has been utilized for the solution of the displacement controlled non-linear problem augmented by the line search algorithm.

As far as the material properties is concerned, the CFRP adherents were modeled as linear orthotropic with the properties listed in Table 2 [27]. On the other hand, the steel adherents were modeled as linear elastic - perfectly plastic materials (bi-linear model) based on the von Mises plasticity model. The Young modulus has been taken equal to $170 \mathrm{GPa}$, the Poisson ratio equal to 0.3 and the yield stress limit equal to $180 \mathrm{MPa}$ (experimentally measured magnitudes). For the description of the constitutive behavior of cohesive elements utilized for modeling the adhesive layer, the 3D proposed EPZ mixed-mode model is utilized. The definition of the pure mode EPZ law properties is based on the corresponding ones described in $[22,23]$. According to the manufacturer of the adhesive material, the shear strength of the adhesive $\sigma_{\mathrm{c}, \mathrm{II}}$ (not the adhesive's bulk shear strength, but the one measured through SLJ tests) varies together with the substrates utilized for the creation of the adhesive bond. The manufacturer provides the shear strength measured from adhesively bonded SLJ geometries from similar materials, including CFRP-to-CFRP. Additionally, he states that when analyzing adhesive joints with dissimilar materials, as the SLJ cases adopted herein, the selection of the $\sigma_{\mathrm{c}, \mathrm{II}}$ magnitude must be based on the corresponding lower value measured from SLJ with similar adherents. In the case of the present adhesive and for an adhesive layer with $0.5 \mathrm{~mm}$ thickness, the $\sigma_{\mathrm{c}, \mathrm{II}}$ magnitude equals to $18.5 \mathrm{MPa}$ (a shear strength of $18 \mathrm{MPa}$ was obtained with the thick adherend shear test in [28]) and 14.25 MPa, for steel-to-steel and CFRP-to-CFRP substrates, respectively. Thus, in our case for the $0.5 \mathrm{~mm}$ thick adhesive layer the $\sigma_{\mathrm{c}, \mathrm{II}}$ magnitude has been taken equal to $14.25 \mathrm{MPa}$. The remaining parameters have been taken equal to the respective ones listed in Table 3 $[22,23]$ which correspond to steel-to-steel adhesive joints. The Mode I fracture toughness $J_{\text {Ic }}$ provided by the manufacturer and utilized herein is equal to $4 \mathrm{~N} / \mathrm{mm}$ (measured according to ISO 4578), whereas the corresponding value measured by DCB tests in [29] is approx. equal to $0.45 \mathrm{~N} / \mathrm{mm}$, which differs by an order of magnitude from the one utilized in this work. However, numerical simulations of the joints have been conducted, by considering a value of $J_{\text {Ic }}$ equal to $0.45 \mathrm{~N} / \mathrm{mm}$ or $4 \mathrm{~N} / \mathrm{mm}$ and the remaining parameters the same for both analyses, and there was no effect on the global response of the tested specimens. This is reasonable since in the SLJ geometry, the adhesive fails mostly under Mode II stresses and thus the contribution of Mode I is relatively small. Additionally, this is an indication that the key parameter in the intrinsic cohesive law shape adopted herein is rather the critical stress than the fracture toughness value. This issue will be covered in detail in an upcoming article.

The aforementioned parameters refer to an adhesive layer with a thickness of $0.5 \mathrm{~mm}$. In the framework of the current numerical analysis, an additional adhesive thickness has been considered equal to $0.85 \mathrm{~mm}$. However, according to the experimental work reported in [30,31], the parameters of the cohesive laws are affected by the thickness of the corresponding bondline, in Mode I and II loading and fracture, respectively. More specifically, the parameters significantly affected are the critical stresses $\sigma_{\mathrm{c}, \mathrm{I}}$ and $\sigma_{\mathrm{c}, \mathrm{II}}$. The authors in $[30,31]$ have shown that a $1 \mathrm{~mm}$ thick adhesive layer yields a $14.7 \%$ decrease and a $4.5 \%$ increase in the $\sigma_{\mathrm{c}, \mathrm{I}}$ and $\sigma_{\mathrm{c}, \mathrm{II}}$ magnitudes, respectively, of the corresponding magnitudes obtained from a $0.5 \mathrm{~mm}$ thick adhesive layer. Table 3 presents the corresponding parameters utilized for the definition of the pure mode EPZ laws of the 3D interface elements for the simulation of the seven SLJ cases. Set 1 corresponds to cases SLJ-1, SLJ-3, SLJ-5 and SLJ-7 whereas Set 2 corresponds to cases SLJ-2, SLJ-4 and SLJ-6. Parameter $e$ has been taken equal to $0.1 \%$ as concluded from previous investigations [22-25].

\section{Experimental and numerical results}

\subsection{Prediction of failure loads}

A comparison between the experimental and numerical failure loads is presented in Fig. 5 for all cases. According to Fig. 5, the

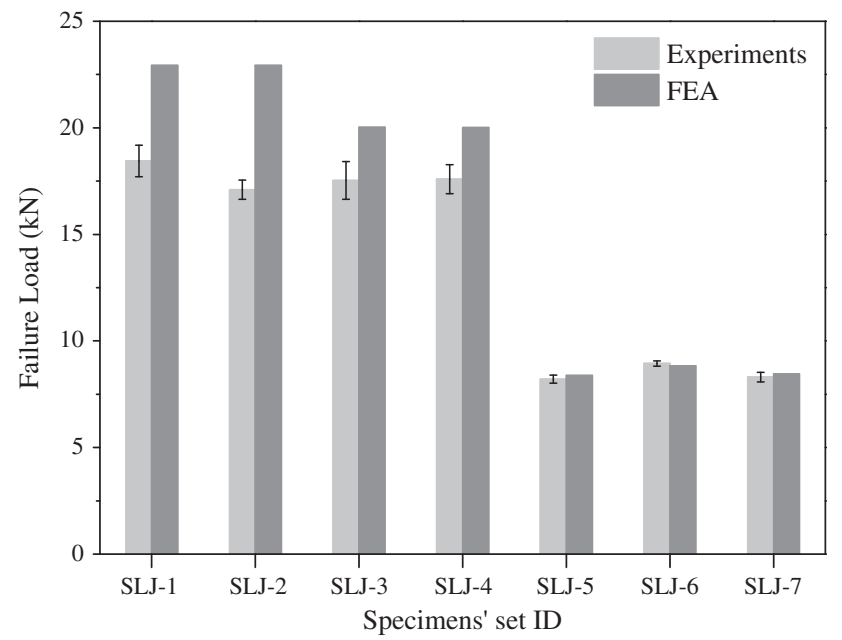

Fig. 5. Collected experimental and numerical failure loads for all SLJ cases considered.

Table 2

Orthotropic elastic properties of the CFRP adherents.

\begin{tabular}{|c|c|c|c|c|c|c|c|c|}
\hline$E_{1}(\mathrm{MPa})$ & $E_{2}(\mathrm{MPa})$ & $E_{3}(\mathrm{MPa})$ & $v_{12}$ & $v_{13}$ & $v_{23}$ & $G_{12}(\mathrm{MPa})$ & $G_{13}(\mathrm{MPa})$ & $G_{23}(\mathrm{MPa})$ \\
\hline 35,000 & 3000 & 3000 & 0.35 & 0.3 & 0.3 & 2000 & 1500 & 1500 \\
\hline
\end{tabular}

Table 3

Parameters of the pure mode EPZ laws utilized in simulation of the CFRP-to-steel SLJ tests.

\begin{tabular}{|c|c|c|c|c|c|c|c|}
\hline Magnitude units & $k_{\mathrm{I}}\left(\mathrm{N} / \mathrm{mm}^{3}\right)$ & $k_{\mathrm{II}}=k_{\mathrm{III}}\left(\mathrm{N} / \mathrm{mm}^{3}\right)$ & $\sigma_{\mathrm{c}, \mathrm{I}}(\mathrm{MPa})$ & $\sigma_{\mathrm{c}, \mathrm{II}}=\sigma_{\mathrm{c}, \mathrm{III}}(\mathrm{MPa})$ & $J_{\text {Ic }}(\mathrm{N} / \mathrm{mm})$ & $J_{\text {III }}=J_{\text {IIIC }}(\mathrm{N} / \mathrm{mm})$ & $e(\%)$ \\
\hline Set 1 & 3700 & 1300 & 30 & 14.25 & 4 & 4.7 & 0.1 \\
\hline Set 2 & 2176 & 765 & 25.6 & 15 & 4 & 4.7 & 0.1 \\
\hline
\end{tabular}


numerical values are in very good agreement with respect to the experimentally measured values for the short, $25 \mathrm{~mm}$ overlap length cases (SLJ-5, 6 and 7), having a maximum difference equal

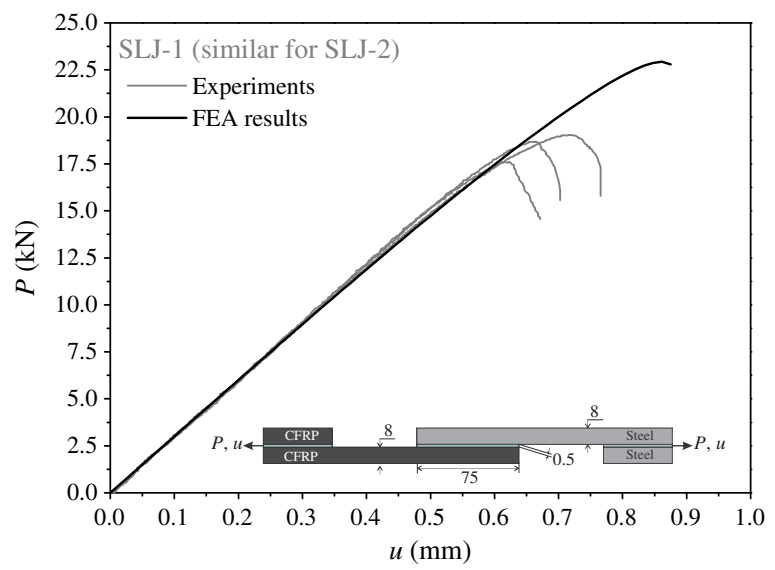

(a)

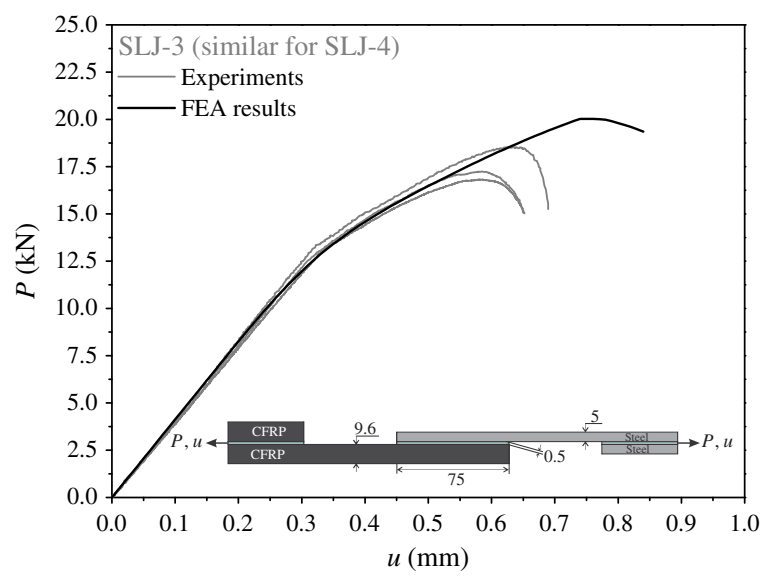

(b)

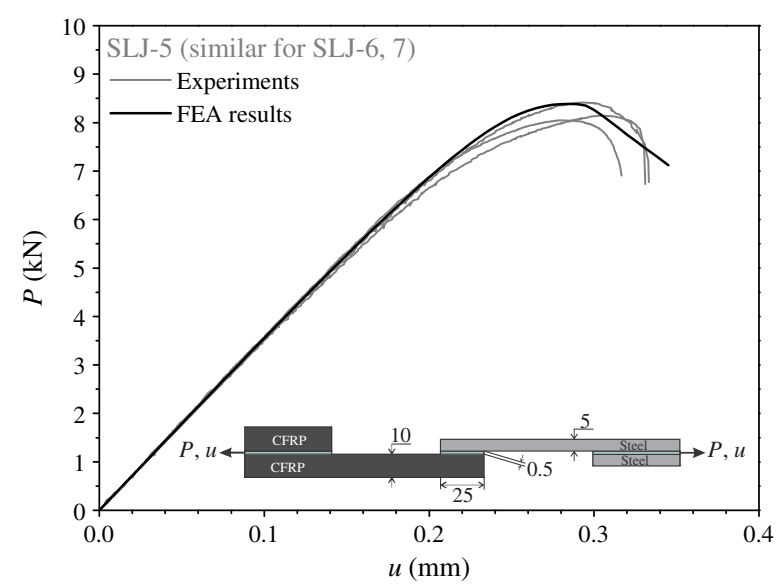

(c)

Fig. 6. Experimentally registered and numerically evaluated global response of SLJ1 (a), SLJ-3 (b) and SLJ-5 (c) cases considered. to $2.2 \%$. On the other hand, there is a maximum difference equal to $25 \%$ for the cases with a $75 \mathrm{~mm}$ long overlap length (SLJ-1, 2, 3 and 4 cases). A simple calculation of the joints' strength with $L_{\mathrm{o}}=75 \mathrm{~mm}$ and $t_{\mathrm{S}}=5 \mathrm{~mm}$ (SLJ-3 and SLJ-4), based on initial yielding of the adherent by the formula $F_{\max }=S_{\mathrm{y}} \cdot A$ [32], where $S_{\mathrm{y}}$ is yield stress limit equal to $180 \mathrm{MPa}$ and $A$ is the cross-sectional area equal to $w t_{\mathrm{s}}$, yields $F_{\max } \approx 21.5 \mathrm{kN}$; a value that is almost equal to the one predicted with CZM techniques but differs $22 \%$ to the experimental values. Additionally, as shown in the first part of this paper series [26] a very good prediction of the strength of joints with short overlap length (SLJ-5 to SLJ-7) is made by using the formula $F_{\max }=\tau_{\mathrm{a}} \cdot L_{0} \cdot w$ proposed in [28].

As concluded in the experimental part of this paper series (Part I), the average shear strength $\tau_{\mathrm{s}}$ of the adhesive layer, which was experimentally measured (failure load/adhesive area) from the short overlap length joints, was equal to the corresponding property provided by the adhesive's manufacturer. This particular value was utilized as the critical stress parameter in the pure Mode II law and thus the numerical failure load agrees with the experimental one. It is noteworthy that the same key parameters have been utilized for the EPZ laws for all seven cases, which are based on material properties of the adhesive layer. The maximum deviation of the measured $\tau_{\mathrm{s}}$ magnitude from the $75 \mathrm{~mm}$ overlap length joints and the one provided by the manufacturer, is equal to $22 \%$, a value that is in agreement with the difference calculated from the numerical and experimental failure load. Considering the above, it will be shown later that this difference is attributed to the development and evolution of a non-uniform shear stress field at the adhesive layer during its loading history compared to the one of the $25 \mathrm{~mm}$ overlap length joints which is uniform.

Regardless of these differences, the utilized EPZ laws and mixed-mode model capture with great accuracy the global response of the adopted joints in terms of their stiffness change, as shown in Fig. 6. In particular, the proposed modeling procedure has captured the linear elastic behavior as well as all types of the upcoming non-linearities, i.e. plasticity and damage/fracture of the adhesive and plasticity of the steel (SLJ-3 and SLJ-4 cases).

\subsection{Stress variations in the adhesive layer of SLJ-1 to SLJ-4 cases}

Fig. 7 presents the variation of the principal stresses at the experimentally maximum attained force level of SLJ-1 and SLJ-2 cases. The top substrate is the steel one, whereas the bottom substrate is the CFRP one. According to the calculated deformed shape of the SLJ-1 and 2 models, the CFRP substrate, which is more compliant than the steel one, deforms in accordance with the wellknown eccentric behavior of a single lap joint in a way that leads

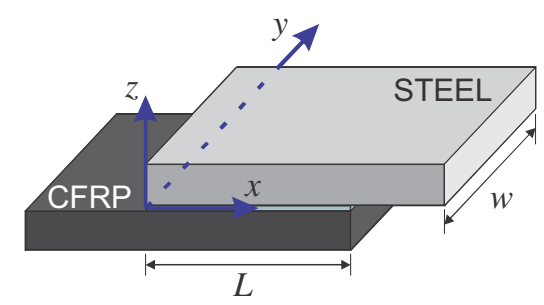

Fig. 8. Dimensions and coordinate system of the overlap area of the SLJ configurations.

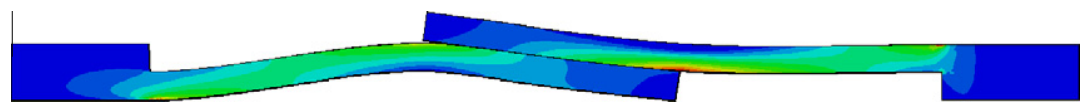

Fig. 7. Qualitative variation of principal stresses over the SLJ domain of SLJ-1 and SLJ-2 cases (75 mm overlap length, and 8 mm thick steel substrate). 
the adhesive layer to develop high peel and in-plane shear stresses at the right and the left hand side edges of the bondline (cohesive zone - fictitious crack), respectively. Further insight can be given by examining the developed stresses over the adhesive area, as calculated with the proposed EPZ mixed-mode model. Figs. 9-11 present the developed peel $\sigma_{\mathrm{z}}$, in-plane $\sigma_{\mathrm{xz}}$ and out-of-plane $\sigma_{\mathrm{yz}}$ shear stresses over the adhesive layer, respectively, according to the local coordinate system depicted in Fig. 8, as calculated from the SLJ-1 model. Without any loss of significant information, stress variations of the SLJ-2 model are not provided, since they share the same behavior with the SLJ-1 model. The axes of the 2D stress figures have been normalized according to the real dimensions of the overlap length and width of the model. In fact, the plotted stresses are obtained by the mixed-mode EPZ model (see Section 2) and thus $\sigma_{\mathrm{z}}, \sigma_{\mathrm{xz}}$ and $\sigma_{\mathrm{yz}}$ correspond to the Mode I $\sigma_{\mathrm{I}}$, Mode II $\sigma_{\mathrm{II}}$ and Mode III $\sigma_{\text {III }}$ tractions.

The peel stresses plotted in Fig. 9 are calculated at the maximum experimental force level of the SLJ-1 model. Apart from the symmetry with respect to the $x$ axis at $y / w=0.5$ that they exhibit, they peak at $x / L=1$. This behavior is common through the entire

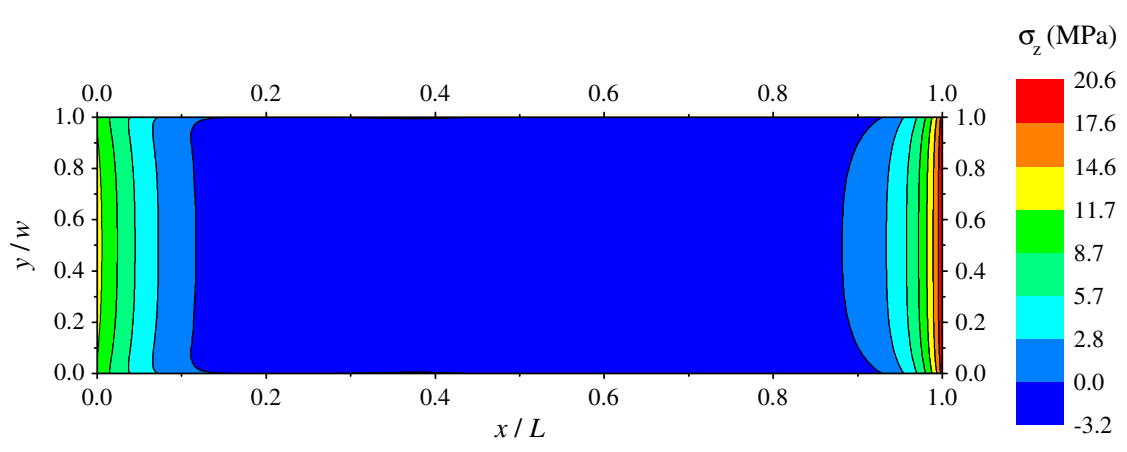

Fig. 9. Peel stresses $\sigma_{\mathrm{z}}$ distribution over the adhesive area of the SLJ-1 model at the maximum attained force.
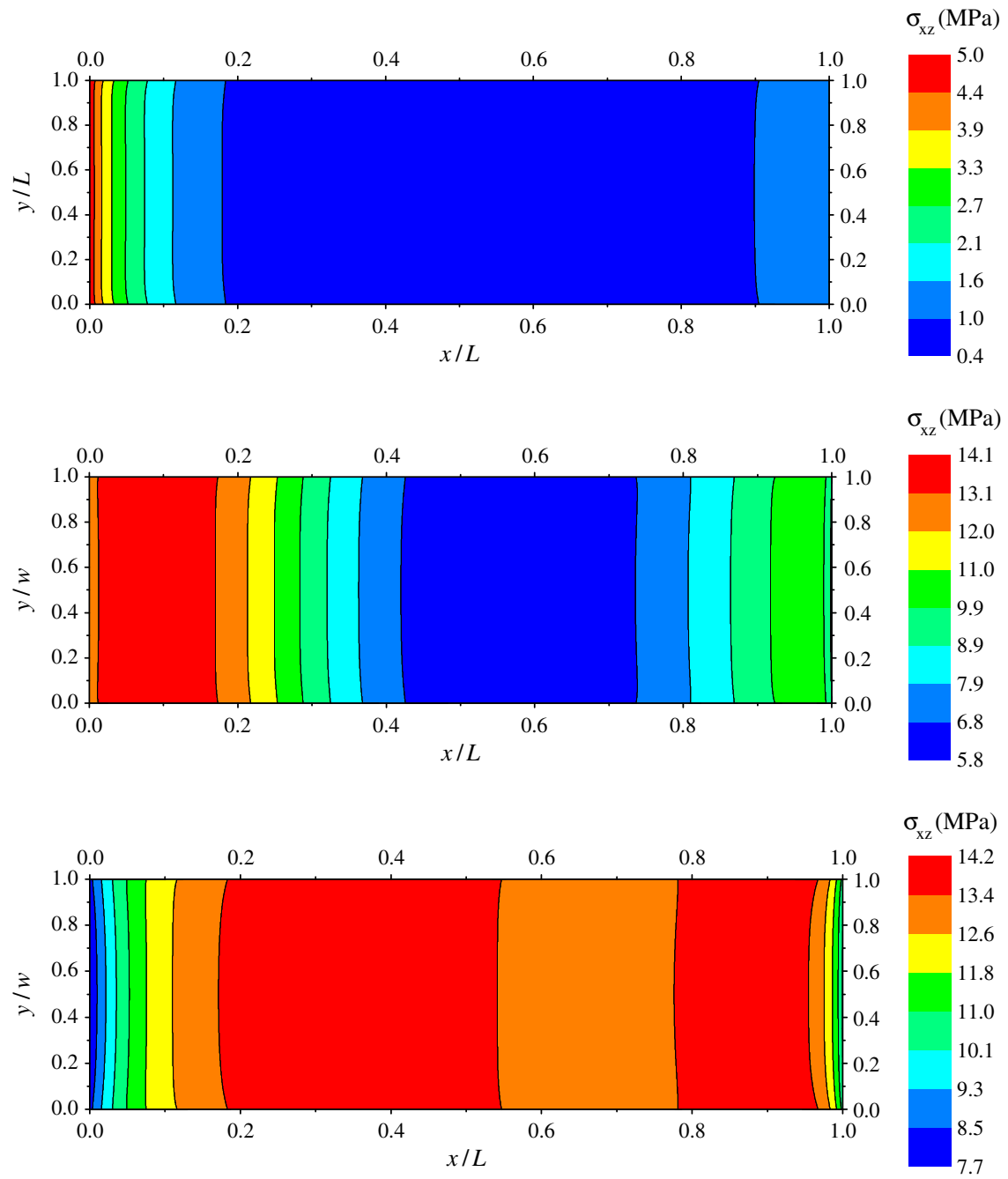

Fig. 10. In plane shear stresses $\sigma_{\mathrm{xz}}$ distribution over the adhesive area of the SLJ-1 model for $u$ equal to $0.1 \mathrm{~mm}$ (a), $0.5 \mathrm{~mm}$ (b) and $0.86 \mathrm{~mm}$ (maximum loading) (c). 
loading history of the SLJ model. On the other hand, in-plane shear stresses peak at $x / L=0$ within the linear elastic region of the adhesive material (see Fig. 10a). As loading increases and the adhesive layer enters plasticity, the in-plane shear stresses almost reach the plateau of 14.2 MPa (see Fig. 10b). The plastic zone then extends in that area with any further increase in the load and at the same time the adhesive material laying in the right hand side, at $x / L=1$, contributes to the loading by developing elastic stresses. At the maximum attained force, the plasticity of the adhesive layer has extended and damage initiation and propagation is located at both adhesive edges (area of the softening behavior of the T-S law), as shown in Fig. 10c. However the rate and magnitude of the damage extension is much higher at $x / L=0$, a fact that has as a consequence the deformed shape of Fig. 7, where the cohesive zone is apparent at the left hand side of the overlap area.

The out-of-plane shear stresses (Mode III) remain at very low levels and can be characterized as linear during the entire loading history of the SLJ-1 or SLJ-2 models, as shown in Fig. 11. Thus they do not contribute to the mixed-mode loading and fracture of the adhesive layer. This conclusion was expected since the problem under examination is in fact plane strain and hence, dominant fracture modes are Mode I and Mode II. They peak at the vicinity of the two corner edges of the adhesive layer, that is at $x / L=0$ and $y / w=0$ and 1.

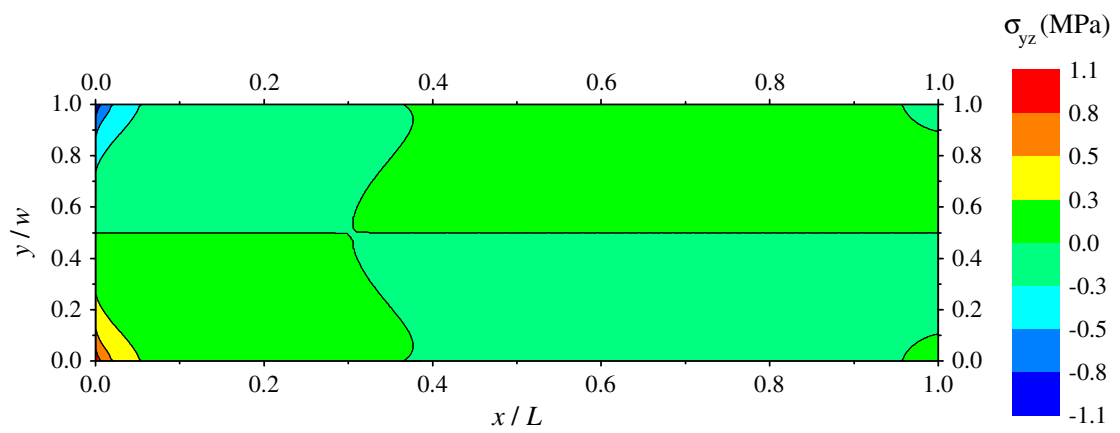

Fig. 11. Out-of-plane shear stresses $\sigma_{\mathrm{yz}}$ distribution over the adhesive area of the SLJ-1 and SLJ-2 model at the maximum attained force $(u=0.86$ mm).

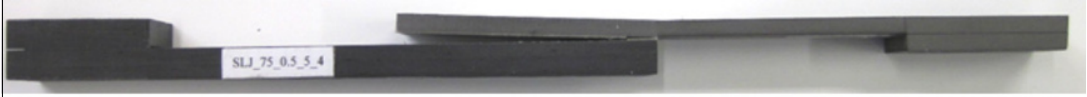

(a)

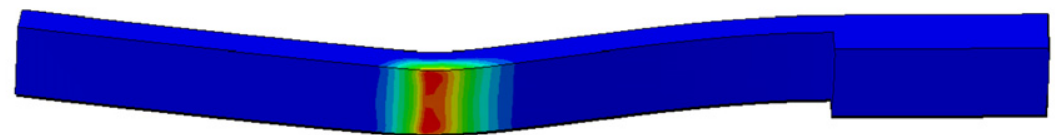

(b)

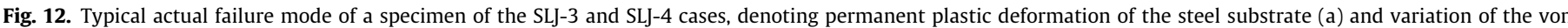
Mises plastic strains over the steel adherent domain after the failure of the joint.

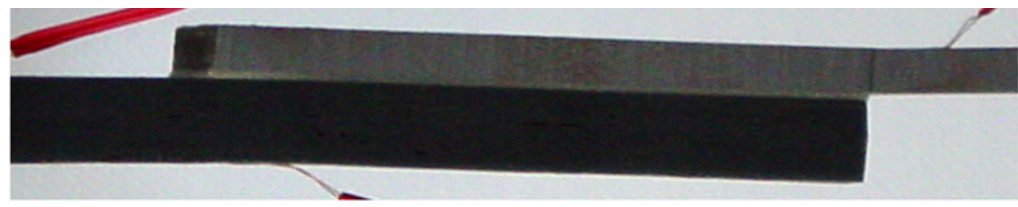

(a)
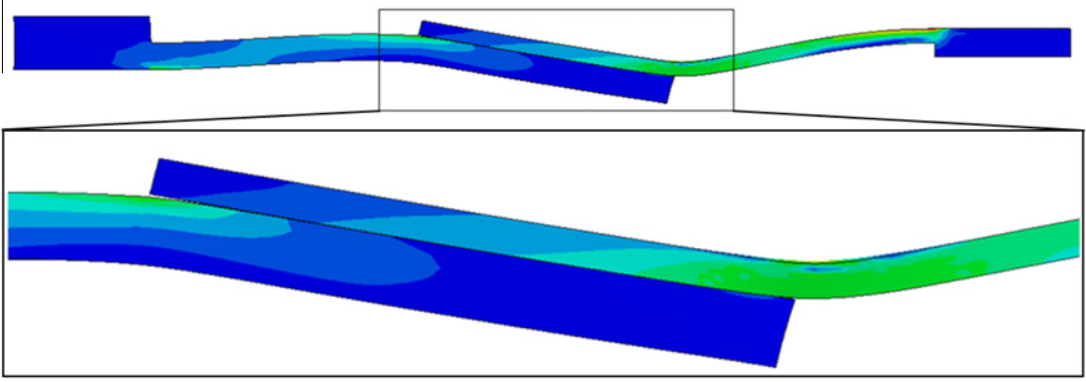

(b)

Fig. 13. Typical deformed shape near the maximum attained force as experimentally captured (a) and numerically predicted (b). 


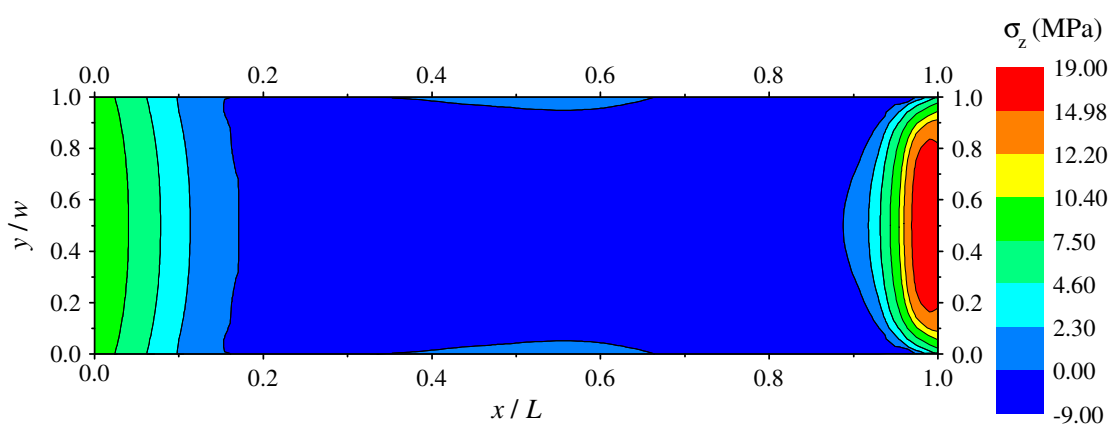

(a)

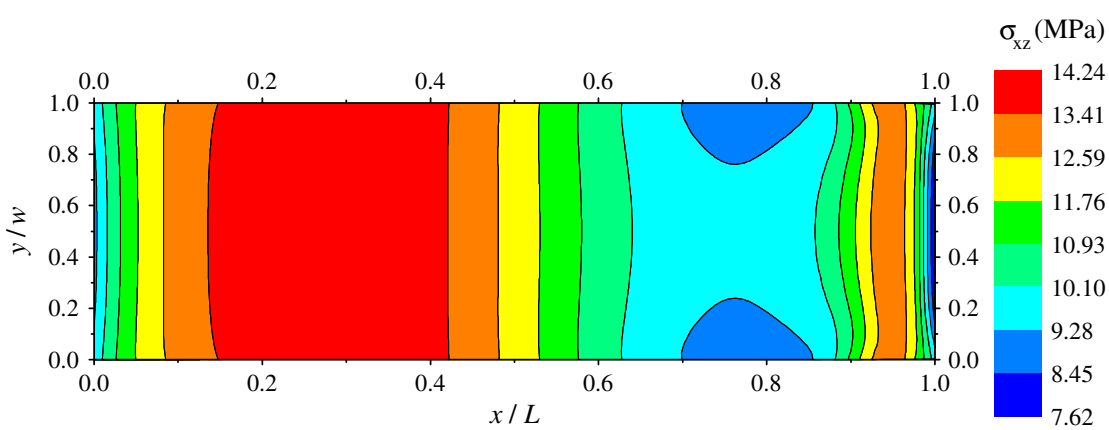

(b)

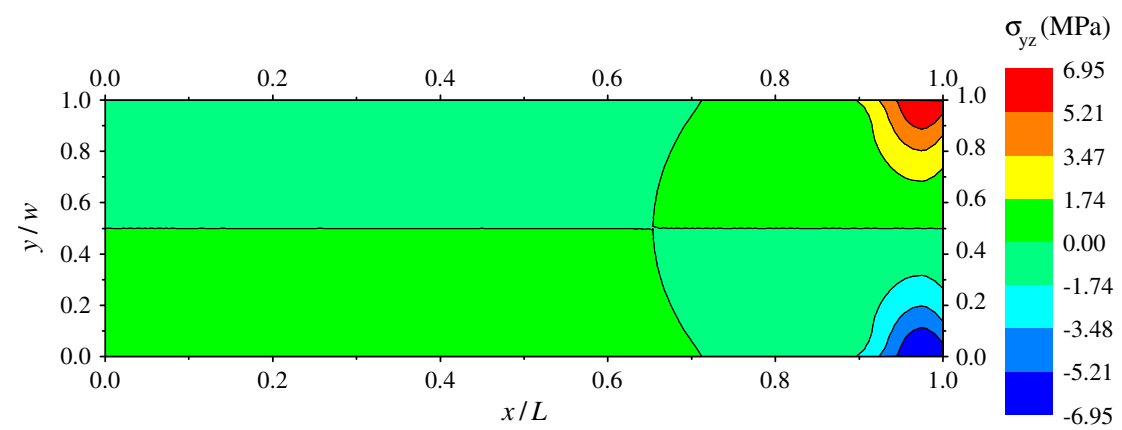

(c)

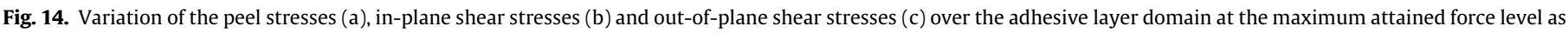
calculated with the SLJ-3 model (the same for SLJ-4 model).

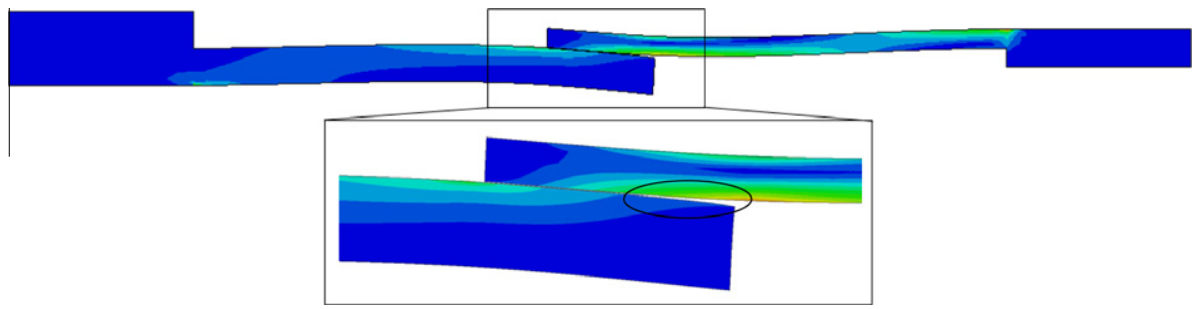

Fig. 15. Qualitative variation of principal stresses over the SLJ domain of SLJ-5 and SLJ-6 cases.

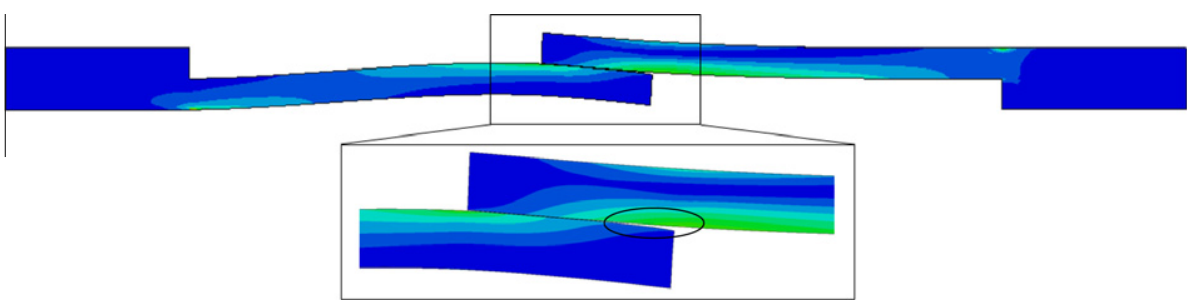

Fig. 16. Qualitative variation of principal stresses over the SLJ domain of SLJ-7 case. 
Fig. 12a presents a typical SLJ-3 specimen (the same occurs with the SLJ-4 specimens) after failure of the bond, where the permanent deformation of the steel adherent is evident. The developed plastic zone in the steel adherent is presented in Fig. $12 \mathrm{~b}$, as numerically calculated with the use of a bi-linear (elastic perfectly plastic) material model for the ductile steel substrate.

The local yield of the steel adherent has a significant effect on the loading and fracture mode of the adhesive bond. A comparison between the experimentally captured and numerically calculated deformation in Fig. 13 reveals at first hand the damage evolution process within the adhesive layer. The experimental observations are in good agreement with the numerical results shown in this figure. According to Fig. 13a, an extensive damage zone (plasticity, void nucleation and micro-cracking) has been developed at the left hand side edge of the adhesive layer, whereas a smaller damage zone seems to form at the right hand side edge of the adhesive layer (whitened areas). This behavior is similar to the corresponding one described previously, for the SLJ-1 and SLJ-2 cases.

In order to conduct confident conclusions regarding the effect of the yield zone developed in the steel adherend, the peel stress $\sigma_{\mathrm{z}}$, the in-plane shear stresses $\sigma_{\mathrm{xz}}$ and the out-of-plane shear stresses $\sigma_{\mathrm{yz}}$ as these vary over the adhesive layer at the maximum attained force level are shown in Fig. 14. The peel stresses follow the same pattern to that presented in Fig. 9 within the linear elastic region and early stages of plasticity of the adhesive layer. With further increase in the applied force and as the steel adherent enters plasticity, high peel stress concentrate in a larger area than that of Fig. 9, as shown in Fig. 14a. This redistribution, where the peel stresses peak in the area around $x / L=1$ bounded within $[y / w=0.2, y /$ $w=0.8$ ] and decrease in magnitude in the areas bounded within $[y / w=0, y / w=0.2]$ and $[y / w=0.8, y / w=1.0]$ is attributed to the subsequent redistribution of the out-of-plane shear stresses as shown in Fig. 14c. The $\sigma_{\mathrm{yz}}$ stresses follow the pattern presented in Fig. 11 within the linear elastic and early stages of plasticity of the adhesive layer. However, the plastic zone developed in the steel adherent leads to the shrinkage of its width at that location (see Fig. 12b), which subsequently leads the adhesive material to develop increased out-of-plane shear stresses. Thus, the contribution of the Mode III fracture mode to the failure of the SLJ-3 and SLJ-4 cases is considered important. The in-plane shear stresses follow the pattern shown in Fig. 10a and b within the linear elastic and early stages of plasticity of the adhesive layer, respectively. However, with the yield initiation of the steel adherent, the inplane shear stresses redistribute in a way that at the maximum attained load they present the variation shown in Fig. 14b. This behavior is much different than the one presented in Fig. 10c,

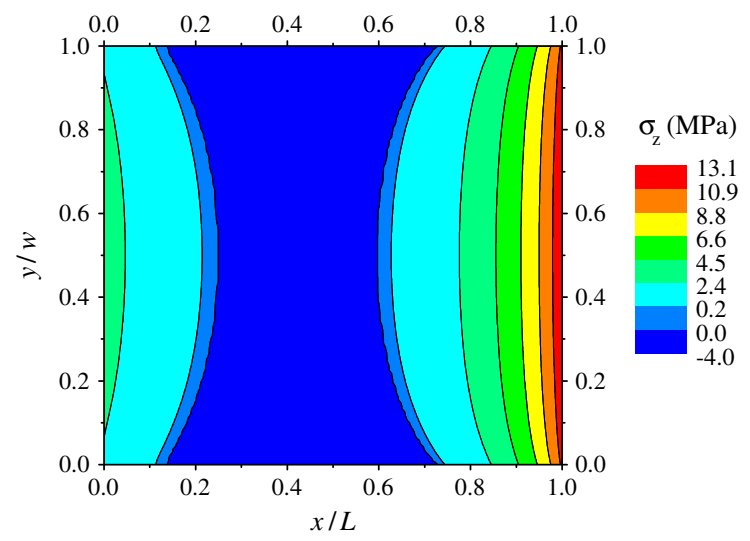

Fig. 17. Variation of the peel stresses (over the adhesive layer domain at the maximum attained force level as calculated with the SLJ-5 model (the same for SLJ6 and SLJ-7 model). which corresponds to the SLJ-1 and SLJ-2 cases and where plasticity in the steel adherent is not present.

\subsection{Stress variations in the adhesive layer of SLJ-5 to SLJ-7 cases}

Figs. 15 and 16 present the distribution of the principal stresses over the SLJ-5 (similar for SLJ-6) and SLJ-7 deformed models, respectively. According to these figures, regardless of the stiffness ratio and the adhesive thickness, in all three cases, damage and
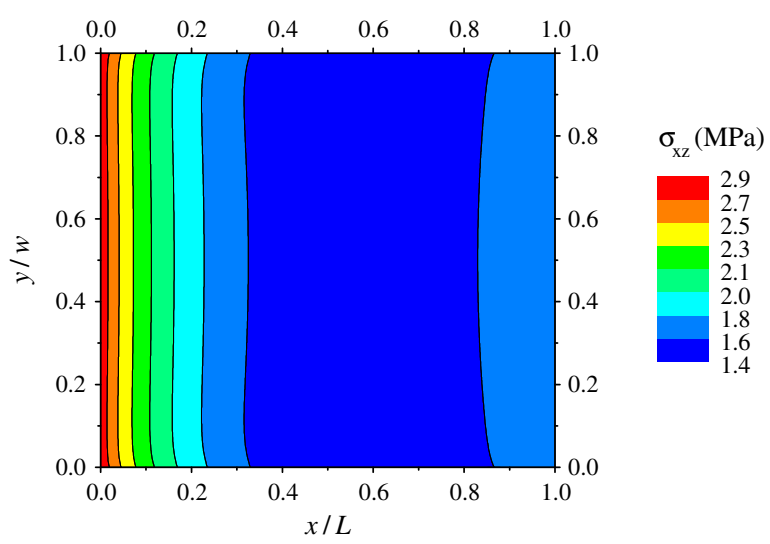

(a)

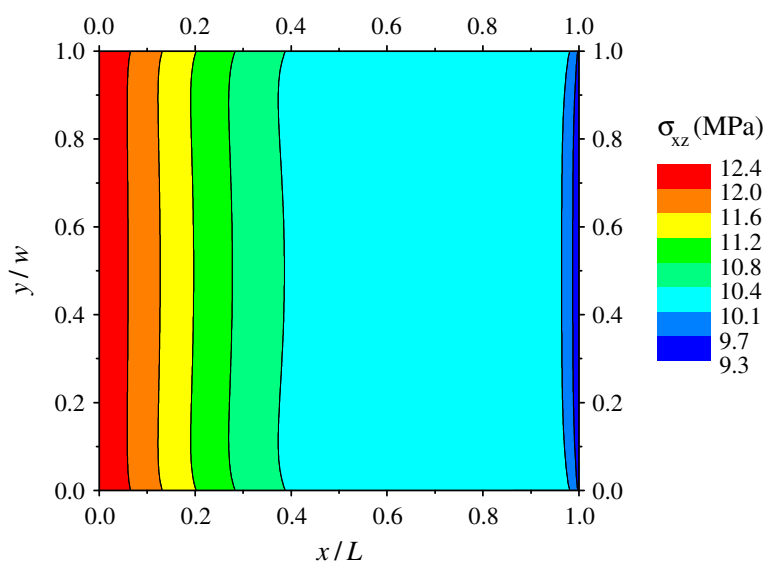

(b)

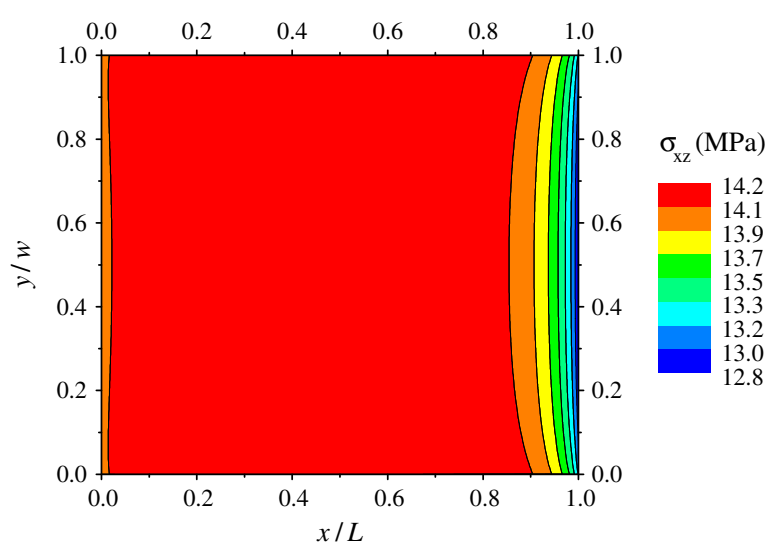

(c)

Fig. 18. Variation of the in-plane shear stresses $\sigma_{\mathrm{xz}}$ over the adhesive layer domain at the elastic region (a), early stages of plasticity (b) and at the maximum attained force level (c) as calculated with the SLJ-5 model (the same for SLJ-6 and SLJ-7 model). 


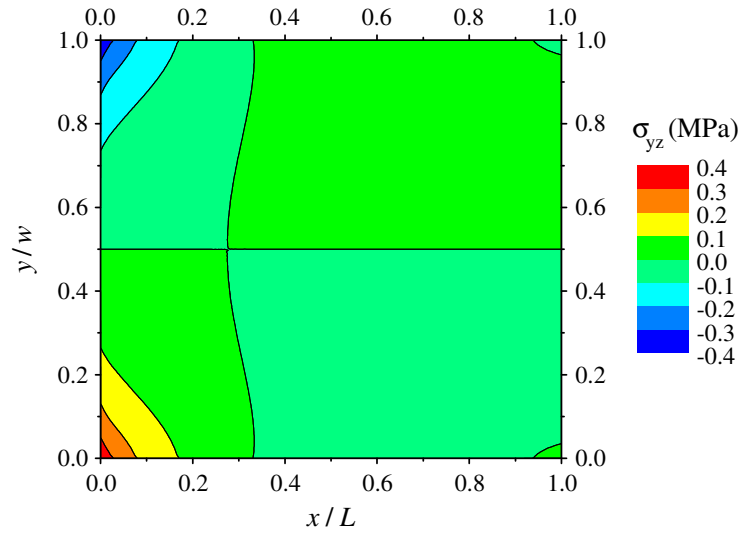

Fig. 19. Variation of the out-of-plane shear stresses $\sigma_{\mathrm{yz}}$ over the adhesive layer domain at the maximum attained force level as calculated with the SLJ-5 model (the same for SLJ-6 and SLJ-7 model).

cracking initiates at the right hand side edge of the adhesive overlap area, under Mode I loading and fracture conditions. This statement can be further justified by examining the variation of the corresponding to Mode I peel stresses $\sigma_{\mathrm{z}}$ over the adhesive area, as shown in Fig. 17. The positive peel stresses that contribute to Mode I loading and fracture develop in the areas bounded by $[x \mid$ $L=0, x / L=0.25]$ and $[x / L=0.6, x / L=1]$, whereas in the remaining area negative contact stresses develop that denote contact conditions. The positive peel stresses peak at $x / L=1$ with magnitude equal to $13.1 \mathrm{MPa}$. On the other hand, the in-plane shear stresses in the linear elastic region peak at the opposite edge at $x / L=0$ (see Fig. 18a) and thus plasticity in the adhesive layer initiates from that point and propagates towards the remaining adhesive edge at $x / L=1$ (see Fig. 18b). Finally, at the maximum attained load, the in-plane shear stresses have become plastic in almost the entire adhesive area and decrease (softening) in the vicinity of the adhesive edge at $x / L=1$, as shown in Fig. 18c. As aforementioned, at this location peel stresses maximize and thus they become responsible for damage and fracture initiation of the adhesive layer.

The out-of-plane shear stresses $\sigma_{\mathrm{yz}}$ peak, in the entire loading history, at the two left hand side corner of the adhesive layer at the $x / L=0$, as shown in Fig. 19. Their magnitude remains at very low stress levels and thus $\sigma_{\mathrm{yz}}$ stresses remain in the linear elastic region, without contributing to the failure of the adhesive layer.

\section{Conclusions}

This work is the second part of an integrated study of CFRP-tosteel adhesively bonded joints with thick adherents. An effort was made herein for simulating the seven tested single lap joint cases, by utilizing advanced numerical tools based on cohesive zone modeling techniques. The main objective of the current work was to provide an insight to the behavior of the tested cases, in terms of exploring the loading and fracture response of the adhesive layer, both occurring under mixed-mode conditions. A phenomenological cohesive law and a mixed-mode model, formulated according to the embedded process zone approach, have been utilized for the numerical description of the constitutive response of the adhesive layer. The same key parameter magnitudes have been utilized for the pure mode laws in all cases.

The modeling procedure followed managed to capture with good accuracy the global behavior of the simulated joints. The failure loads of the joints with $25 \mathrm{~mm}$ and $75 \mathrm{~mm}$ overlap length were predicted with a maximum difference equal to $2.2 \%$ and $25 \%$, respectively, with respect to the experimentally obtained magni- tudes. It has been concluded that the adhesive layer of the short overlap joints enters plasticity in a more uniform manner compared to the long overlap joints, a fact that justifies the differences in the failure loads.

In general, there is a minor effect of the out-of-plane shear stresses (Mode III) to the loading and failure of the adhesive layer, as long as the steel adherent remains in its elastic material region. On the other hand, when the steel enters plasticity, peel, in-plane and out-of-plane shear stresses redistribute in the adhesive layer and in particular in the vicinity of the steel's plastic hinge. This leads to the development of high out-of-plane shear stresses which contribute significantly to the adhesive's mixedmode failure.

\section{References}

[1] da Silva LFM, das Neves PJC, Adams RD, Spelt JK. Analytical models of adhesively bonded joints - Part I: literature survey. Int J Adhes Adhes 2009;29:319-30.

[2] da Silva LFM, das Neves PJC, Adams RD, Wang A, Spelt JK. Analytical models of adhesively bonded joints - Part II: comparative study. Int J Adhes Adhes 2009;29:331-41.

[3] Dvorak G, Zhang J, Canyurt O. Adhesive tongue-and-groove joints for thick composite laminates. Compos Sci Technol 2001;61:1123-42.

[4] Yan ZM, You M, Yi XS, Zheng XL, Li Z. A numerical study of parallel slot in adherent on the stress distribution in adhesively bonded aluminum single lap joint. Int J Adhes Adhes 2007;27:687-95.

[5] Pires I, Quintino L, Durodola JF, Beevers A. Performance of bi-adhesive bonded aluminium lap joints. Int J Adhes Adhes 2003;23:215-23.

[6] Vallée T, Correia JR, Keller T. Optimum thickness of joints made of GFPR pultruted adherents and polyurethane adhesive. Compos Struct 2010;92:2102-8.

[7] Papanikos P, Tserpes KI, Labeas G, Pantelakis S. Progressive damage modelling of bonded composite repairs. Theoret Appl Fract Mech 2005;43:189-98.

[8] Odi RA, Friend CM. An improved 2D model for bonded composite joints. Int J Adhes Adhes 2004;24:389-405.

[9] Zhao X, Adams RD, da Silva LFM. Single lap joints with rounded adherend corners: stress and strain analysis. J Adhes Sci Technol 2011;25:819-36.

[10] Zhao X, Adams RD, da Silva LFM. Single lap joints with rounded adherend corners: experimental results and strength prediction. J Adhes Sci Technol 2011;25:837-56.

[11] Chen Z, Adams RD, da Silva LFM. Prediction of crack initiation and propagation of adhesive lap joints using an energy failure criterion. Eng Fract Mech 2011;78:990-1007.

[12] Panigrahi SK, Pradhan B. Three dimensional failure analysis and damage propagation behaviour of adhesively bonded single lap joints in laminated FRP composites. J Reinf Plast Compos 2007;26:183-201.

[13] Zhang Y, Vassilopoulos PA, Keller T. Mode I and II fracture behaviour of adhesively bonded pultruted composite joints. Eng Fract Mech 2010;77:128-43.

[14] da Silva LFM, Campilho RDSG. Advances in Numerical Modeling of Adhesive Joints. Springer Briefs in Applied Sciences and Technology - Computational Mechanics; 2011 http://dx.doi.org/10.1007/978-3-642-23608-2_1.

[15] Goyal VK, Johnson ER, Goyal VK. Predictive strength-fracture model of composite bonded joints. Compos Struct 2008;82:434-46.

[16] Campilho RDSG, de Moura MFSF, Domingues JJMS. Modelling single and double - lap repairs on composite materials. Compos Sci Technol 2005:65:1948-58.

[17] Kafkalidis MS, Thouless MD. The effects of geometry and material properties on the fracture of single lap-shear joints. Int J Solids Struct 2002;39:4367-83.

[18] Yang QD, Thouless MD, Ward SM. Numerical simulations of adhesivelybonded beams failing with extensive plastic deformation. J Mech Phys Solids 1999;47:1337-53.

[19] Yang QD, Thouless MD. Mixed - mode fracture analyses of plastically deforming adhesive joints. Int J Fract 2001;110:175-87.

[20] Campilho RDSG, de Moura MFSF, Domingues JJMS. Stress and failure analyses of scarf repaired CFRP laminates using a cohesive damage model. J Adhes Sci Technol 2007;21:855-970.

[21] Campilho RDSG, de Moura MFSF, Domingues JJMS. Using a cohesive damage model to predict the tensile behaviour of CFRP single-strap repairs. Int J Solids Struct 2008;45:1497-512.

[22] Anyfantis KN, Tsouvalis NG. A novel traction-separation law for the prediction of the mixed mode response of ductile adhesive joints. Int J Solids Struct 2012;49:213-26.

[23] Anyfantis KN, Tsouvalis NG. A 3D ductile constitutive mixed-mode model of cohesive elements for the finite element analysis of adhesive joints. J Adhes Sci Technol, in press.

[24] Anyfantis KN, Tsouvalis NG. Analysis of an adhesively bonded single lap joint subjected to eccentric loading. Int J Adhes Adhes, in press.

[25] Anyfantis KN. Finite element predictions of composite-to-metal bonded joints with ductile adhesive materials. Compos Struct 2012;94:2632-9. 
[26] Anyfantis KN, Tsouvalis NG. Loading and fracture response of CFRP-to-steel adhesively bonded joints with thick adherents - Part I: experiments. Compos Struct 2013;96:850-7

[27] Anyfantis KN, Tsouvalis NG. Experimental parametric study of single-lap adhesive joints between dissimilar materials. In: Proceedings of the ECCM15 15th European conference on composite materials, Venice, Italy, 24-28 June; 2012.

[28] da Silva LFM, Carbas RJC, Critchlow GW, Figueiredo MAV, Brown K. Effect of material, geometry, surface treatment and environment on the shear strength of single lap joints. Int J Adhes Adhes 2009;29:621-32.
[29] de Moura MFSF, Campilho RDSG, Gonçalves JPM. Crack equivalent concep applied to the fracture characterization of bonded joints under pure mode loading. Compos Sci Technol 2008;68:2224-30.

[30] Ji G, Ouyang Z, Li G. Effects of bondline thickness on Mode-II interfacial laws of bonded laminated composite plate. Int J Fract 2011;168:197-207.

[31] Ji G, Ouyang Z, Li G, Ibekwe S, Pang SS. Effects of adhesive thickness on global and local Mode-I interfacial fracture of bonded joints. Int J Solids Struct 2010;47:2445-58.

[32] Grant LDR, Adams RD, da Silva LFM. Experimental and numerical analysis of single lap joints for the automotive industry. Int J Adhes Adhes 2009;29:405-13. 